\title{
VALORES ORGANIZACIONAIS E RACIONALIDADES: UMIA VISITA AO TERCEIRO SETOR
}

\author{
Jones Louback* \\ Maria Luisa Mendes Teixeira** \\ Diógenes de Souza Bido***
}

RESUMIO

s valores humanos atuam como guias orientando a vida de indivíduos, grupos, organizações e sociedades. Os valores organizam-se em duas dimensões bipolares: Autotranscendência versus Autopromoção e Abertura à Mudança versus Conserva ção. A primeira se refere, respectivamente, à orientação para o outro versus para si próprio; e a segunda, à valorização da independência de pensamento e ação versus preservação de costumes, de normas e segurança material. Tendo em vista que as racionalidades subjazem às ações, este trabalho teve como objetivo investigar a relação entre as dimensões bipolares de valores e as racionalidades substantiva e instrumental. Esta pesquisa dedicou-se ao estudo de Organizações do Terceiro Setor, por estas se constituírem em espaço privilegiado para uma atuação baseada na racionalidade substantiva. Optou-se pela estratégia de pesquisa multicaso, empregando técnicas quantitativas e qualitativas. Os resultados evidenciaram a existência de relação entre racionalidades e as dimensões de valores de Autotranscendência e Autopromoção dos valores organizacionais. Porém, outros fatores, como o momento histórico de surgimento da organização e crenças religiosas, ou espirituais, mostraram-se importantes na explicação da relação encontrada.

Palavras-chave: Valores organizacionais. Racionalidades. Terceiro setor. Organizações Não Governamentais.

\author{
Organizational Values and Rationalities: \\ AN INCURSiON INTO THE THIIRD Sector
}

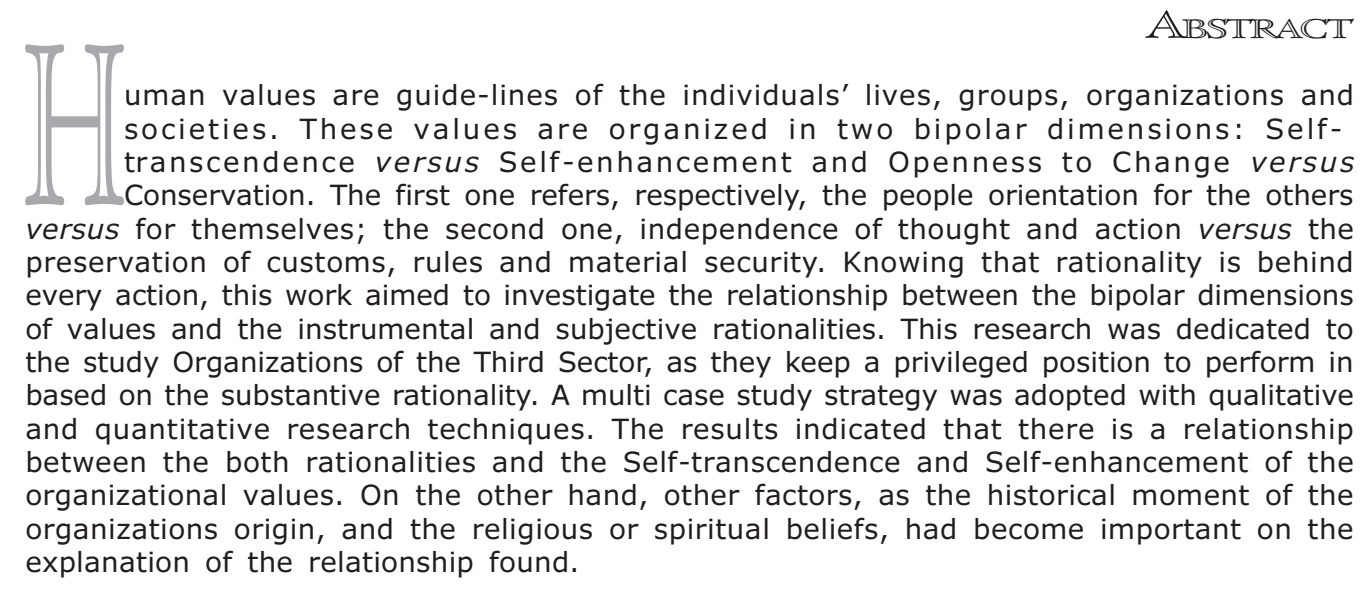

Key words: Organizational Values. Rationality. Third Sector. Non Governmental Organizations.

* Doutorando em Administração de Empresas pela Universidade Presbiteriana Mackenzie. Prof. da Pós-Graduação Lato Sensu da Universidade Presbiteriana Mackenzie (SP). Pesquisador do Núcleo de Estudos sobre Gestão Baseada em Valores - MackGVAL. Endereço: Rua Antonio Gonçalves da Cruz, 60 apto 113B. São Paulo/SP, CEP 05029-060. E-mail: joneslouback@gmail.com

** Doutora em Administração de Empresas pela Faculdade de Economia e Administração da Universidade de São Paulo - FEA/USP. Prof. do Programa de Pós-Graduação em Administração de Empresas do Centro de Ciências Sociais e Aplicadas da Universidade Presbiteriana Mackenzie. Coord. do Núcleo de Estudos sobre Gestão Baseada em Valores - MackGVAL. E-mail: mallu@mackenzie.com.br

*** Doutor em Administração de Empresas pela FEA-USP. Prof. do Programa de Pós-Graduação em Administração da Universidade Presbiteriana Mackenzie. E-mail: diogenesbido@yahoo.com.br 
Inntrodurção

presente trabalho busca compreender a relação entre valores organizacionais e racionalidades em organizações do Terceiro Setor. O universo do Terceiro Setor é composto, segundo Teodósio (2003), por diferentes organizações, tais como fundações, projetos sociais, sindicatos, igrejas e outros. Alves (2002a) propõe em substituição, ou mesmo sinônimo de Terceiro Setor, o uso da sigla ONG (Organizações Não-Governamentais) como um termo guarda-chuva, adotado, neste trabalho, para designar todo e qualquer tipo de organização pertencente ao Terceiro Setor.

A história das associações voluntárias no Brasil remonta ao período da colonização portuguesa, e possui dois pilares básicos: de um lado, um sistema de plantio controlado pelo senhor da senzala, do qual todos dependiam, com um sistema de troca envolvendo lealdade e serviços versus proteção e favor; e do outro lado, a união da Igreja com o Estado, com uma Igreja Católica enfraquecida e o serviço de filantropia relegado às Confrarias, organizações ligadas à Igreja Católica, mas dirigida por leigos (LANDIM, 1997).

Ao longo do século XIX, o Estado passa a assumir serviços sociais anteriormente desenvolvidos pela Igreja Católica, e a proclamação da República, em 1889, e a sua constituição de 1891, separando Igreja-Estado, força os clérigos a uma busca de novas associações com a população e instituições, para garantia dos seus recursos, e a implantação de escolas, hospitais e instituições de caridade. A chegada de imigrantes de origem Anglicana, Luterana, Presbiteriana, Metodista e Batista, entre outras denominações, conduz, também, a uma criação de escolas e universidades similares às organizadas pela Igreja Católica (LANDIM, 1997).

No final do século XIX e início do século XX, as associações voluntárias proliferam pelo país, migrando gradualmente da ligação com igrejas e lojas maçônicas, para a composição de grupos com interesses políticos e profissionais. Esse fato desperta no Estado o desejo de controlá-los ou reprimi-los, de tal forma, que a partir de 1930, com o governo de Getulio Vargas, o Estado torna-se o principal financiador da área social; passa, então, a implementar políticas autoritárias e paternalistas e a utilizar a prerrogativa de declarar, com todos os benefícios legais, se uma organização é ou não de utilidade pública (ADRIANO, 2002; LANDIM, 1997).

Com o fim do período ditatorial de 1937-1945, verifica-se uma participação mais intensa da sociedade civil, com crescimento das organizações sem fins lucrativos, buscando a promoção dos direitos humanos, trabalho voluntário, cultura, educação, influenciadas pelos debates políticos e ideológicos que surgiam (LANDIM, 1997).

Com o golpe de 1964, surgem organizações que enfatizam a luta contra ditadura e, por essa razão, sofrem restrições e controles por parte do Estado. Também, nesse período aparecem as associações comunitárias que buscavam soluções para problemas locais da população e, por aparentemente não representarem ameaças, são toleradas pelas autoridades políticas (ALVES, 2002a; FERNANDES, 1994).

O processo de redemocratização, na década de 1980, propiciou um novo tipo de parceria das ONGs com um Estado outrora opositor, e facilitou o surgimento de novas organizações, com preocupações voltadas para as áreas de saúde, educação, cidadania, inserção social, entre outras (FERNANDES, 1994; LANDIM, 1997; TENÓRIO, 2001).

As ONGs são vistas por Serva (1993), Vidal et al (2004) e outros como organizações substantivas, posição da qual discorda Alves (2002b) e, parcialmente, questionada por Siqueira Pinto (2003), permanecendo o debate sobre as racionalidades e o Terceiro Setor também na voz de outros autores (MACIEL DE LIMA; HOPFER; SOUZA-LIMA, 2004; TENÓRIO, 1999).

Na visão de Guerreiro Ramos (1981), a história do homem sempre foi marcada por uma racionalidade substantiva, ainda que o termo nunca tenha sido emprega- 
do por pensadores, na qual há o predomínio da ética sobre a vida em geral, e os costumes e as tradições são livres dos condicionamentos do sistema; preservando, na socialização, aquilo que de certa forma já estava arraigado na psique do indivíduo.

Guerreiro Ramos (1981), citando Mannheim ${ }^{1}$ (1940), defende que na sociedade moderna a racionalidade instrumental (Zweckrationalitat), determinada por uma expectativa de resultados ou fins "ponderados e perseguidos racionalmente" (WEBER, 1999, p. 15), "tende a abranger a totalidade da vida humana, não deixando ao indivíduo médio outra escolha além da desistência da própria autonomia" (GUERREIRO RAMOS, 1981, p. 7).

Além disso, o autor sugere, baseado em Mannheim (1940), que "um alto grau de desenvolvimento técnico e econômico pode corresponder a um baixo desenvolvimento ético" (GUERREIRO RAMOS, 1981, p. 7). A conclusão "é que nas sociedades industriais, a lógica da racionalidade instrumental, que amplia o controle da natureza, ou seja, o desenvolvimento das forças produtoras, se tornou a lógica da vida humana em geral, [impondo o desenvolvimento capitalista] limites à livre e genuína comunicação entre os seres humanos" (GUERREIRO RAMOS, 1981, 13). A racionalidade instrumental caracteriza, portanto, a cultura da sociedade de mercado, inerente às sociedades industriais, e sendo a estas também inerente. Assim, pode-se entender que as racionalidades, substantiva ou instrumental, fazem parte da cultura das sociedades.

Os valores pessoais são desenvolvidos mediante processos de socialização (SCHWARTZ, 1992), assim como os valores organizacionais (OLIVEIRA; TAMAYO, 2004), sendo a sua origem de natureza cultural. Os valores são o centro da cultura e se constituem em programas mentais que orientam a vida das pessoas e grupos numa sociedade (HOFSTEDE, 1980).

Os valores fazem parte da cultura organizacional, juntamente com as práticas, os símbolos, os rituais e heróis (HOFSTEDE et al., 1990) e "atuam como elementos integradores, no sentido de que são compartilhados por todos ou pela maioria dos membros organizacionais" (OLIVEIRA; TAMAYO, 2004, p. 130).

Os estudos realizados sobre esse tema (SCHWARTZ, 1992) indicam que os valores podem ser classificados em duas dimensões bipolares: orientação para o outro (Autotranscendência) versus orientação para si (Autopromoção); orientação para a Conservação versus orientação para Abertura à Mudança. Isso nos remete a pensar nas racionalidades apontadas por Weber (1999), relacionando-as a valores: a) racionalidade orientada para os fins (instrumental), relacionada a valores de Autopromoção; b) racionalidade orientada para valores (substantiva), relacionada com valores de Autotranscendência, indicando uma preocupação com o outro; c) racionalidades instrumental e substantiva relacionada a valores de Conservação ou de Abertura a Mudanças, em menor ou maior grau.

Sendo ambos, racionalidades e valores, elementos de origem cultural, propôs-se para este trabalho o seguinte problema de pesquisa: como os valores organizacionais se relacionam com as racionalidades substantiva e instrumental nas organizações do Terceiro Setor?

Esta pesquisa teve como objetivo geral investigar a relação entre as dimensões bipolares de valores e as racionalidades substantiva e instrumental, e como objetivos específicos: a) identificar os valores organizacionais e as racionalidades substantiva e instrumental das organizações pesquisadas; b) compreender relações entre valores organizacionais, incluindo suas dimensões bipolares, e as racionalidades substantiva e instrumental.

Assim, teve-se como propósito adentrar o debate sobre racionalidades e organizações do Terceiro Setor sob a perspectiva dos valores organizacionais.

A estrutura do artigo segue a seguinte ordem: após a introdução, apresenta-se o referencial teórico discutindo a relação entre racionalidades, substantiva e instrumental, e valores organizacionais. A seguir são apresentados os procedimentos metodológicos da pesquisa, seguidos da apresentação, análise e interpretação dos dados. Por último, realiza-se uma discussão dos resultados e apresentam-se as conclusões.

${ }^{1}$ MANNHEIM, K. Men and society in age of reconstruction. New York: Harcourt, Brace \& World, 1940. 
Numa perspectiva crítica da racionalidade instrumental, encontram-se trabalhos como os de Guerreiros Ramos (1981), Serva (1993; 1997) e Siqueira Pinto (2003). Guerreiro Ramos (1981), fortemente influenciado por Polanyi (1975), critica a supremacia do econômico sobre as demais dimensões da vida e fundamenta os seus estudos sobre a racionalidade nas organizações por meio da teoria denominada por ele de "teoria substantiva da vida associada", sinalizando para o que poderia ser uma organização substantiva (SERVA, 1997). Três qualificações gerais são apresentadas por Guerreiro Ramos (1981), sobre a "teoria formal da vida associativa":

a)primeiro, uma teoria da vida humana associada é substantiva, quando a razão, no sentido substantivo, é sua principal categoria de análise. b) segundo, uma teoria substantiva da vida associada é algo que existe há muito tempo e seus elementos sistemáticos podem ser encontrados nos trabalhos dos pensadores de todos os tempos, passados e presentes, harmonizados ao significado que o senso comum atribui à razão, embora nenhum deles tenha jamais empregado a expressão razão substantiva. c) terceiro, a teoria substantiva, tal como aqui concebida, envolve uma superordenação ética da teoria política, sobre qualquer eventual disciplina que focalize questões da vida humana associada (GUERREIRO RAMOS, 1981, p. 26-27).

Guerreiro Ramos descreve a força modeladora do mercado, cujas organizações que correspondem às suas exigências assumem o "caráter de um paradigma para a organização de toda a existência humana" (1981, p. 92); afirma que, "em sociedade alguma do passado, jamais os negócios foram a lógica central da vida da comunidade, [e que] somente nas modernas sociedades de hoje o mercado desempenha o papel de força central, modeladora da mente dos cidadãos" (1981, p. 114).

A leitura que Guerreiro Ramos (1981) apresenta de Weber reconhece que a sua abordagem das racionalidades não é uma posição dogmática, fundamentalista, diferenciando-se tanto de Adam Smith, que exalta a lógica do mercado como "um ethos da existência humana em geral", quanto de Marx com a sua visão da "história substituindo o homem, como portador da razão" (GUERREIRO RAMOS, 1981, p. 4). Weber teria, assim, escolhido o caminho da resignação (neutralidade versus confrontação), esforçando-se para investigar a temática de sua época, sendo incapaz de resolver a tensão espiritual presente na sua abordagem pelo caminho da racionalidade substantiva. O objetivo de Guerreiro Ramos é oferecer "à especulação, a idéia de que uma teoria substantiva poderia ser formulada com base naquilo que Weber não disse, mas que, provavelmente, diria se tivesse vivido nas presentes circunstâncias históricas" (GUERREIRO RAMOS, 1981, p. 25).

Para Guerreiro Ramos (1981), uma teoria substantiva da vida humana aplicada também às organizações sempre existiu e seus elementos podem ser identificados nos trabalhos dos pensadores, ainda que a expressão "razão substantiva" nunca tenha sido empregada. Como "a economia sempre esteve 'engastada na sociedade', a sociedade capitalista tem que ser entendida como um caso excepcional e não como um padrão para avaliar a história social e econômica" (GUERREIRO RAMOS, 1981, p. 28).

Como as organizações modernas "controlam a ação de seus membros, desenvolvendo vocabulários que escondem algumas partes da realidade e magnificam outras partes" (PERROW², 1972 apud GUERREIRO RAMOS, 1981, p. 119), "definindo, criando e moldando seu ambiente" (GROSS3', 1973 apud GUERREIRO RAMOS,

2PERROW, C. Complex organization: a critical essay. Glenview, Illinois, Scott, Foresman, 1972. ${ }^{3}$ GROSS, B., An organized society? Public Administration Review, July/Aug. 1973. 
1981, p. 119), é proposta uma abordagem substantiva da organização, composta por duas tarefas distintas: "a) o desenvolvimento de um tipo de análise capaz de detectar os ingredientes epistemológicos dos vários cenários organizacionais; e b) o desenvolvimento de um tipo de análise organizacional expurgado de padrões distorcidos de linguagem e conceptualização" (GUERREIRO RAMOS, 1981, p. 118).

Sobre uma nova análise organizacional, Guerreiro Ramos (1981, p. 120) entende que os sistemas sociais que evitam considerações substantivas "deformam, caracteristicamente, a linguagem e os conceitos através dos quais a realidade é apreendida". Por essa razão, propõe uma nova abordagem substantiva da organização, explicitando o que chamou de "pontos cegos" da teoria vigente: 1) o conceito de racionalidade vigente nas organizações estaria impregnado da ideologia segundo a qual o homem é movido somente pelo interesse de ganhos econômicos; 2) a organização econômica atual, formal, não pode ser considerada como o único modelo para julgar todas as organizações ao longo da história; 3) a teoria vigente nas organizações não faz distinção clara entre o significado da existência do homem e a sua sobrevivência biológica; 4) não é apresentada uma distinção clara entre trabalho e ocupação, entendendo o primeiro como "a prática de um esforço subordinado às necessidades objetivas inerentes ao processo de produção em si" e o segundo como "a prática de esforços livremente produzidos pelo indivíduo em busca de sua atualização pessoal excepcional e não como um padrão para avaliar a história social e econômica" (GUERREIRO, 1981, p. 130).

Para Serva (1997), na proposta de Guerreiro Ramos (1981), está incluso o princípio o qual afirma que o indivíduo pode conduzir a sua vida buscando autorealização e, ao mesmo tempo, considerar o direito de outros indivíduos; contrapondo, dessa forma, o modelo organizacional vigente em que o mercado define o que é sucesso e, liberado de exigências éticas, fornece as bases ao abuso do poder, ao domínio, à dissimulação de intenções. O predomínio da razão instrumental seria responsável por último "pela insegurança psicológica, degradação da qualidade de vida, pela poluição, pelo desperdício de recursos" (SERVA, 1997, p. 19) entre outros males, além de produzir uma teoria organizacional desvinculada da necessária gratificação do indivíduo.

Um problema levantado quanto à proposta de Guerreiro Ramos (1981) é que esta foi formulada de uma maneira puramente conceptual, conforme ele próprio afirmou, e não foi continuada, em virtude de sua morte aos 67 anos, um ano depois da publicação da sua obra "A nova ciência das organizações". Os autores brasileiros que criticam a razão instrumental, defendendo a substantiva, não estariam conseguindo comprovar empiricamente a possibilidade de, na gestão, empregar-se a razão substantiva (SERVA, 1997).

Com base no que classificou como um "impasse" - a não demonstração com exemplos organizacionais reais da aplicação da razão substantiva -, Serva (1997) realizou pesquisa de campo com observação participante em três empresas privadas do setor de serviço, localizadas em Salvador, concluindo que duas destas organizações são substantivas, possibilitando o estabelecimento de relações gratificantes entre os seus membros, níveis consideráveis de auto-realização e embasamento das ações numa lógica não utilitária.

Para as organizações do Terceiro Setor que, por um lado estão envolvidas com a promoção do bem comum e suporte social e, por outro, não sofrem pressões para maximização de resultados econômicos, existiria o pressuposto de que são pautadas por uma racionalidade substantiva, constituindo um espaço adequado, inclusive, para as práticas do voluntariado (SIQUEIRA PINTO, 2003; VIDAL et al, 2004).

Siqueira Pinto (2003), buscando entender a racionalidade presente em organizações do Terceiro Setor, realizou pesquisa em uma fundação corporativa com base no modelo proposto por Serva (1997) e chegou à conclusão de que, apesar das suas atividades-fins, existia uma predominância de referenciais instrumentais. Para o autor, esta predominância poderia ser explicada por algumas peculiaridades das fundações empresariais: "porte, abrangência de atuação, volume de recursos aportados, fiscalização do Ministério Público e influência" (SIQUEIRA PINTO, 2003, p. 340). 
Conforme exposto, têm-se pesquisas em organizações lucrativas e não lucrativas, com identificação de racionalidades instrumentais e substantivas, ainda que no caso do Terceiro Setor, a tendência seja de "baixos níveis de racionalidade instrumental e formalidade e altos níveis de solidariedade e troca direta com o seu público" (SEIBEL; ANHEIER ${ }^{4}, 1990$ apud ALVES, 2002b, p. 7). Alves (2002a) defende que existem diferenças entre os tipos de organizações, mas seriam diferenças em termos relativos e não absolutos. Ainda que em organizações do Terceiro Setor a informalidade possa contribuir para o desenvolvimento de redes informais, que possibilitem acesso a determinadas fontes de recursos, a informalidade também pode estar sustentada por um comportamento instrumental, visando à maximização de resultados.

Vallores organizacionais

A revisão de literatura de valores permite identificar que o estudo de valores tem suas raízes na filosofia e sua abordagem empírica encontra-se no âmbito das ciências sociais, com o foco em valores pessoais, desde a primeira metade do século XX. No âmbito dos valores culturais, os estudos desenvolveram-se a partir da última década daquele século. Nessa mesma época, são desenvolvidos os estudos sobre valores organizacionais, no âmbito da cultura organizacional, como parte integrante desta e sob abordagens teóricas a ela direcionadas. Enquanto constructo, no entanto, os valores organizacionais têm sido objeto de preocupação da Psicologia Organizacional, com raízes na Psicologia Social, e foram motivados por preocupações diversas. Entre estas, destacam-se: Hofstede et al (1990), buscando compreender a relação entre valores organizacionais e cultura organizacional, caminho seguido, no Brasil, por Ferreira et al (2002); O'Reilly, Chatman e Caldwell (1991), com o foco em analisar o fenômeno da congruência entre empregados e organizações; Tamayo e colaboradores, com o objetivo de estudar os valores percebidos pelos empregados como sendo os compartilhados pelas organizações (TAMAYO; GONDIM, 1996; TAMAYO; MENDES; PAZ, 2000; OLIVEIRA; TAMAYO, 2004).

Desses estudos, os únicos que se apóiam em uma teoria de valores propriamente dita são os realizados por Tamayo e colaboradores nos anos 2000 e 2004, já que o estudo realizado em 1996 por Tamayo e Gondim (1996) não se embasava em uma teoria de valores como, posteriormente, o próprio Tamayo reconheceu em trabalhos seguintes.

Os estudos de Tamayo e colaboradores realizados em 2000 e 2004 assentam-se na teoria de valores de Schwartz, desenvolvida a partir da segunda metade dos anos 80, cujo artigo seminal foi publicado em 1992.

A teoria de valores de Schwartz, baseada no estudo dos valores pessoais, busca avançar os estudos de Rokeach, desenvolvidos na década de 70, o qual classificou os valores pessoais em terminais e instrumentais. Os primeiros estão relacionados a finalidades de vida e os segundos, um meio para realizar os primeiros, os quais se subdividiam em valores relacionados à competência e à moral. Essa classificação, porém, não foi corroborada por Schwartz (SCHWARTZ; BILSKY, 1987; SCHWARTZ, 1992), tendo o mesmo proposto uma teoria de valores composta por duas dimensões bipolares: Autotranscendência versus Autopromoção e Abertura à Mudança versus Conservação. A primeira contrapondo a ênfase na igualdade entre as pessoas e a preocupação com o bem-estar dos outros versus a busca de sucesso pessoal e domínio sobre os outros. A segunda, a ênfase na independência de pensamento e favorecimento da mudança versus a ênfase na submissão, preservando práticas tradicionais e protegendo a estabilidade. Essas dimensões congregam valores que mantêm entre si relações de compatibilidade e oposição. Nessa teoria, baseou-se o trabalho de Oliveira e Tamayo (2004).

4SEIBEL, Wolfgang; ANHEIER, Helmut (orgs). The third sector: comparative Studies of Nonprofit Organizations. Berlin: Walter De Gruyter. 1990. 
Posteriormente, Schwartz (1999) irá também se ocupar de valores culturais propondo uma estrutura que resguarda relações de oposição e compatibilidade, envolvendo três dimensões: Conservadorismo versus Autonomia; Hierarquia versus Igualitarismo; e Domínio versus Harmonia. Nessa teoria, baseia-se o trabalho de Tamayo, Mendes e Paz (2000).

Os estudos de valores organizacionais desenvolvidos por Tamayo e colaboradores têm, portanto, a vantagem de terem sido desenvolvidos considerando a realidade brasileira e basearem-se em uma teoria da valores, propriamente dita.

Valores organizacionais são os valores percebidos pelos empregados como sendo efetivamente característicos da organização (TAMAYO, 1998) e constituem-se em princípios ou crenças, organizados hierarquicamente, relativos a tipos de estrutura ou a modelos de comportamento desejáveis que orientam a vida da empresa e estão a serviço de interesses individuais, coletivos ou mistos (TAMAYO; GONDIM, 1996).

Essa definição de valores organizacionais tem o seu respaldo no conceito de valores de Schwartz e Bilsky (1987, p.551), para os quais os valores são "princípios ou crenças, sobre comportamentos ou estados de existência, os quais transcendem situações especificas, guiam a seleção ou a avaliação de comportamentos e eventos e são ordenados por sua importância".

A teoria de valores pessoais de Schwartz (1992) ressalta que os valores representam três categorias de necessidades básicas universais, que são préexistentes a qualquer indivíduo: necessidades biológicas do organismo; necessidades de coordenação e interação social; e necessidades de bem-estar e sobrevivência dos grupos. O processo de socialização dos indivíduos permite o compartilhamento dessas necessidades.

Analogamente, os valores organizacionais respondem a três problemas fundamentais que a organização enfrenta: a) a relação entre o indivíduo e o grupo, tendo em vista a dificuldade de realizar a conciliação das metas e interesses dos indivíduos e do grupo; b) a necessidade de elaborar uma estrutura para garantir o funcionamento da organização; e c) relação continua com o ambiente físico, sociedade e outras organizações (TAMAYO; MENDES; PAZ, 2000).

Neste trabalho, os valores organizacionais foram considerados à luz de Oliveira e Tamayo (2004), baseados na teoria de valores pessoais de Schwartz (1992), por entendermos, em concordância com esses autores, que as organizações são compostas por pessoas que interagem entre si e com outras externas à organização, numa relação com o meio ambiente social.

Vallores organizacionais e racionalidades

Oliveira e Tamayo (2004), ao pesquisarem valores organizacionais com base na teoria de valores pessoais de Schwartz (1992), encontraram oito fatores, considerados valores ou tipos motivacionais já que representam princípios ou guias da vida organizacional, constituindo-se em metas a serem alcançadas. Esses valores estão em correspondência com os valores pessoais de Schwartz (1992) e são os seguintes:

Fator 1 - Valor Realização: apresenta como meta central o sucesso alcançado pela competência, correspondendo ao valor Realização de valores pessoais;

Fator 2 - Valor Conformidade: valorização do respeito às regras e modelos de comportamento tanto no ambiente de trabalho, como na relação com outras organizações, e corresponde ao valor pessoal Conformidade;

Fator 3 - Valor Domínio: visa à obtenção de status e ao controle sobre pessoas e recursos, e corresponde ao valor Poder de valores pessoais;

Fator 4 - Valor Bem-estar: valorização do bem-estar do empregado e qualidade de vida no trabalho; correspondendo ao valor pessoal Hedonismo que se refere ao prazer e gratificação;

Fator 5 - Valor Tradição: objetiva a preservação aos costumes e às práticas consagradas pela organização, e está em consonância com o valor pessoal Tradição;

Fator 6 - Valor Prestígio organizacional: visa à obtenção de admiração e respeito da sociedade. Este fator está associado ao valor pessoal Poder, assim como o valor Domínio; 
Fator 7 - Abertura aos desafios e valorização do aperfeiçoamento do empregado e da organização, com ênfase na competência, curiosidade, criatividade e variedade de experiência;

Fator 8 - Valor Preocupação com a Coletividade: compreende a preocupação com o relacionamento cotidiano com quem está próximo e com a comunidade, contemplando, por exemplo, valores como a honestidade. Esse valor reflete dois valores pessoais: Universalismo e Benevolência. O primeiro representa o bem-estar de todos e da natureza e o segundo, a promoção do bem-estar de pessoas próximas.

Os valores pessoais de Universalismo e Benevolência estão compreendidos na Dimensão Autotranscendência e podemos considerar que, em princípio, são inerentes à racionalidade substantiva, uma vez que esta dimensão, ao ser vista isoladamente, representa valores de preocupação genuína não só com o outro próximo, mas com a humanidade e a natureza.

O valor organizacional Preocupação com a Coletividade, ao representar os valores pessoais de Universalismo e Benevolência, e, por conseqüência, a dimensão Autotranscendência no âmbito organizacional, pode ser, então, considerado por analogia, isoladamente, como relativo à racionalidade substantiva.

Já os valores organizacionais Realização, Domínio e Prestigio correspondem a valores pessoais que representam a dimensão Autopromoção que privilegia os interesses individuais "mesmo à custa dos outros", e, por conseguinte, podendo ser representantes de racionalidade instrumental.

A dimensão bipolar Autotranscendência versus Autopromoção parece adequada para que possamos analisar as racionalidades nas organizações, tendo como base a teoria de valores organizacionais fundamentada na teoria de valores pessoais de Schwartz (1992), tendo em vista as preocupações humanas que fundamentam os pólos daquela dimensão. Já a dimensão Abertura à Mudança versus Conservação não apresenta o mesmo potencial para contribuir com a análise das racionalidades, uma vez que não diz respeito à relação com o outro.

Weber (1999), ao abordar as racionalidades, inseriu-as no estudo da ação social, entendendo-a como uma ação orientada pelo comportamento dos outros, podendo ser este passado, presente ou esperado como futuro. "Os 'outros' podem ser indivíduos e conhecidos, ou uma multiplicidade indeterminada de pessoas completamente desconhecidas" (WEBER, 1999, p. 14).

Por outro lado, note-se que, ao nos referirmos à relação entre valores organizacionais e racionalidades, empregamos propositalmente a palavra "isoladamente", isto porque tanto os valores de Autotranscendência, quanto os de Autopromoção, embora sendo opostos, ambos estão presentes na realidade humana e social, um modificando o outro. Um não exclui o outro, mas podem manter entre si uma relação de predominância. O mesmo, analogamente, ocorrendo com as racionalidades: uma não excluindo a outra, mas ambas estarem presentes nas ações humanas; e se consideradas associadas a valores, podendo manter entre si uma relação de predominância.

Para Weber, raramente as ações orientam-se por uma ou por outra racionalidade - substantiva, ou instrumental:

Só muito raramente a ação, e particularmente a ação social, orienta-se exclusivamente de uma ou de outra destas maneiras. E naturalmente, esses modos de orientação de modo algum representam uma classificação completa de todos os tipos de orientação possíveis, senão tipos conceitualmente puros, criados para fins sociológicos, dos quais a ação real se aproxima mais ou menos ou dos quais - ainda mais freqüentemente - ela se compõe (WEBER, 1999, p. 16).

Procedinnerntos $\mathbb{M}$ Letodológicos

A estratégial dle pesqurisal

A pesquisa foi realizada mediante estudo multicaso já que a proposta consistiu em estudar racionalidades a partir da perspectiva dos valores organizacionais no âmbito de organizações, especificamente, do Terceiro Setor. 
Os estudos de caso admitem tanto a pesquisa qualitativa, quanto estudos contemplando ambas: a qualitativa e a quantitativa (YIN, 2005). Essa última foi a opção para este trabalho, apesar dos estudos envolvendo racionalidades contemplarem a pesquisa qualitativa. Embora os valores organizacionais possam ser identificados por meio de pesquisa qualitativa, tal abordagem é, principalmente, adotada quando o objetivo consiste em analisar a cultura organizacional, sob a ótica de proposta teórica relativa a este último constructo.

Valores organizacionais compartilhados têm sido estudados, enquanto constructo, sob a perspectiva da Psicologia Social, mediante abordagem quantitativa, como nos estudos de O'Reilly, Chatman e Caldwell (1991), Hofstede et al (1990) e, no Brasil, por Tamayo e seus colaboradores (TAMAYO; GONDIM, 1996; TAMAYO; MENDES; PAZ, 2000; OLIVEIRA; TAMAYO, 2004). Os estudos qualitativos têm contemplado os valores organizacionais declarados como os que são realizados por Kabanoff e Holt (1996).

Uma vez que neste trabalho o objetivo não reside em estudar a relação entre cultura e racionalidades, ou os valores declarados a aquelas, mas contemplar os valores compartilhados, optou-se por realizar o estudo multicaso, utilizando a pesquisa quantitativa para identificar a hierarquia dos valores organizacionais e a relação destes com as racionalidades, e pesquisa qualitativa com o objetivo de compreender essa relação.

\section{Seleção das unidades de análise}

Tendo em vista a opção por estudo de casos com pesquisa quantitativa e qualitativa, decidiu-se realizar a pesquisa em ONGs com mais de 50 colaboradores, situadas na região metropolitana de São Paulo. A pesquisa quantitativa foi realizada em três organizações, aqui denominadas Alpha, Beta e Gamma, e a pesquisa qualitativa em apenas duas, já que a organização Gamma não aceitou participar desta etapa, alegando que estava passando por um processo de mudança, e que o momento não era oportuno.

\section{Caracterização das unidades de análise}

Foi conduzido um levantamento prévio de informações secundárias que caracterizassem e evidenciassem a atuação dessas empresas como organizações não-governamentais. Para tanto, seguindo as sugestões de Yin (2005), foram analisados documentos formais e oficiais dessas organizações, em torno dos três últimos anos.

\section{a) Organização Alpha}

Fundada em 1928 por um clérigo protestante, teve como objetivo construir uma vila de pequenas casas no interior do estado de São Paulo, onde seriam acolhidas e cuidadas pessoas com tuberculose.

Tendo passado por duas ditaduras, é conhecida como uma entidade de assistência social, recebendo o apoio das igrejas protestantes históricas. Em 2006, a organização atendia diariamente 10 mil pessoas, crianças, jovens e adultos, nas áreas de saúde, educação, lazer e esporte, cultura e arte, e jurídica. São 19 projetos sociais nos quais atuam 400 colaboradores distribuídos em quatro grandes unidades instaladas na Grande São Paulo.

O modelo de gestão caracteriza-se por tradicional/hierárquico, formado por um secretário executivo que responde pela organização perante os stakeholders, e é assessorado por três gerentes responsáveis pelas áreas de captação de recursos e marketing, administrativa e financeira, bem como a área de projetos.

A organização tem como visão "tornar-se referência nacional na elaboração e gestão de programas inovadores que visam à emancipação e reinserção das 
pessoas como sujeitos de direito, à luz dos valores humanos universais e dos princípios cristãos"5, integrando, assim, em seu discurso, uma busca de destaque, inovação e os valores humanos e religiosos esposados.

Os prêmios recebidos pela organização destacam o reconhecimento pela eficiência, busca de produtividade com a manutenção de custos administrativos baixos e a competência da organização na gestão dos recursos e nos programas desenvolvidos.

\section{b) Organização Beta}

A fundadora, de origem alemã, ainda jovem, esteve no Brasil participando durante dois anos de um trabalho social, no estado do Paraná, e após este período retorna à Alemanha, quando decide estudar a pedagogia Waldorf, planejando voltar ao Brasil para dedicar-se a projetos sociais. Seu retorno é facilitado quando recebe um convite para lecionar em uma escola particular de São Paulo, de orientação da pedagogia Waldorf, dirigida aos filhos de alemães e holandeses

Além das aulas em classe, a fundadora, em sua residência, iniciou um trabaIho pedagógico, com a integração de seus alunos adolescentes e as crianças carentes da comunidade; posteriormente, realizou reuniões e discussões com os pais dessas crianças, buscando encontrar soluções para alguns problemas da comunidade, e caminhando para o início do projeto social que idealizara.

Com um início informal, em 1975, conforme descrito, a organização formal ocorre em 1979, atuando nos últimos anos nas áreas de educação, cultura, saúde, social e saúde, representadas por programas desenvolvidos pela organização com a comunidade, tais como ambulatórios, creches, marcenaria, reciclagem, biblioteca, horta comunitária e outros, enfatizando "o desenvolvimento integral do ser humano, por meio da educação, saúde, cultura e desenvolvimento social" (site da organização).

O modelo é de uma gestão orgânica, com um organograma circular integrando três grandes núcleos, cujas lideranças são colaboradores envolvidos no dia-a-dia dos projetos sociais, os quais são considerados como credenciados para liderarem muito mais pela visão, envolvimento, participação do que pela formação. A diretoria da organização, que nos modelos tradicionais de gestão do Terceiro Setor desempenham um papel deliberativo importante, na organização Beta, tem uma posição mais figurativa, para atender somente as exigências legais.

Os líderes desses núcleos podem ser convidados a participarem de um conselho informal, identificado no centro do organograma circular, denominado "metas da associação", responsável pela manutenção e renovação da visão e pela indicação dos caminhos futuros da organização. Os mesmos critérios utilizados na formação da liderança dos núcleos são, também, aplicados na formação deste conselho.

Os projetos desenvolvidos buscam não somente um auxílio direto aos mais necessitados, mas o envolvimento da comunidade na discussão e solução dos seus problemas.

Como na organização Alpha, são destacados no site da organização os vários prêmios recebidos dos diversos órgãos e fundações fomentadores de projetos sociais.

A organização contava com aproximadamente 200 colaboradores em 2006, distribuídos em três núcleos, e a coleta de dados foi realizada em um desses núcleos, onde ficam os principais gestores da organização.

\section{c) Organização Gamma}

Localizada na área central da cidade de São Paulo, a organização atua nas áreas de educação e juventude. Foi fundada, em 1994, com o objetivo de desen-

${ }^{5}$ Visão declarada no site da organização, o qual não está identificado, tendo em vista a preservação da identidade da mesma. 
volver projetos que envolvem formação de educadores e jovens, animação cultural, pesquisa, informação, assessoria a políticas públicas, participação em redes e outras articulações interinstitucionais.

Essa organização tem como missão declarada a promoção dos direitos educativos e dos direitos da juventude, tendo em vista a promoção da justiça social, da democracia participativa e do desenvolvimento sustentável no Brasil.

Diferentemente das duas outras organizações, a organização Gamma não declara nenhuma orientação religiosa ou espiritual. Em seu site, são apresentados os currículos dos participantes, os quais possuem cursos de pós-graduação, como mestrado e doutorado. Sua equipe, em 2005, contava com 50 colaboradores, sendo 39 registrados, 12 estagiários e um voluntário.

No site, é destacada, ainda, a capacidade de realização da organização, como resultado do alto desempenho da equipe e da colaboração de uma ampla rede de parceiros nacionais e internacionais, e compromisso com qualidade e capacidade para inovar.

Embora a pesquisa tenha sido realizada com as três organizações, centrouse, principalmente, nas organizações Alpha e Beta, uma vez que a Gamma não aceitou participar da etapa qualitativa. Assim, sua participação na pesquisa quantitativa ficou limitada, como se poderá verificar mais adiante na apresentação dos resultados da pesquisa.

Pesqurisal quantiturival

O levantamento dos valores organizacionais das três ONGs foi realizado com a aplicação, por auto-preenchimento, de um questionário adaptado do Inventário de Perfis de Valores Organizacionais - IPVO, desenvolvido por Oliveira e Tamayo (2004).

A seleção dos núcleos ou projetos onde seriam aplicados os questionários seguiu a sugestão dos gestores líderes de cada organização. No caso da Alpha, o Secretário Executivo indicou 3 núcleos considerados referências na organização, onde funcionam de forma independente escolas profissionalizantes, internatos para crianças em situações de risco e tuteladas pelo estado, asilo para idosos e atividades esportivas para crianças e jovens. Nesses núcleos distribuídos na Grande São Paulo, foram realizados plantões semanais, durante os quais os questionários eram distribuídos para os colaboradores e aguardava-se o seu preenchimento e devolução.

No caso da organização Beta, foram indicados os três núcleos existentes na Grande São Paulo, com projetos de creches e pré-escola, ambulatório médicoodontológico, centro cultural, bibliotecas, oficinas, horta orgânica, projetos estes que estão distribuídos dentro de três favelas, de tal forma que para se conhecer todas as atividades desenvolvidas, tem-se que andar pela comunidade de moradores. Como na organização Alpha, também ali foram realizados plantões semanais para entrega e recepção de questionários.

No caso da organização Gamma, os questionários foram entregues e recebidos por uma aluna de graduação do curso de Administração de uma universidade, que desempenhou o papel de auxiliar de pesquisa no projeto e que, também, atuava como estagiária da organização.

A adaptação de natureza semântica do questionário foi realizada mediante entrevistas com os gestores das ONGs, com a finalidade de que o questionário pudesse retratar as peculiaridades das ONGs, já que a versão original foi desenvolvida com base em organizações privadas e públicas.

Devido ao fato de se ter adaptado o questionário, foi necessário realizar análise fatorial exploratória de forma a validar a escala frente às dimensões propostas por Schwartz (1992), tomando-se por base os tipos de valores organizacionais propostos por Oliveira e Tamayo (2004). Esse procedimento teve como objetivo garantir que os valores levantados refletissem as dimensões propostas por Schwartz (1992) e, ao mesmo tempo, contrapor a escala à de Oliveira 
e Tamayo (2004), analisando semelhanças e não semelhanças.

Após a validação da escala, foi feita uma análise das assertivas de forma a classificá-las de acordo com as racionalidades substantiva e instrumental.

Em seguida, identificou-se a hierarquia de valores organizacionais de cada uma das organizações estudadas, o que gerou uma primeira analise da orientação por racionalidades e valores de cada uma das ONGs.

Considerou-se como público-alvo os colaboradores que atenderam aos seguintes critérios: ser colaborador efetivo da organização, incluindo os funcionários registrados pelo regime de CLT e eventuais funcionários terceirizados, ou temporários, assim como estagiários; e pertencer a todo e qualquer nível hierárquico dentro dessas organizações. A amostra caracterizou-se como não-probabilística e acidental, já que os questionários foram distribuídos e coletaram-se os que tiveram retorno espontâneo.

\section{Pesquisal qurallitartival}

A pesquisa qualitativa foi realizada para atender à segunda parte dos objetivos específicos, que diz respeito à compreensão das relações encontradas entre as dimensões bipolares de valores e racionalidades.

A coleta dos dados foi feita mediante roteiro semi-estruturado, elaborado com base nos processos organizacionais levantados por Serva $(1993,1997)$, e definidos como "aqueles nos quais os indivíduos definem, mediante ações específicas, o caráter básico do empreendimento grupal do qual participam. Assim, os membros delineiam seus padrões de inter-relação e as fronteiras e os limites da ação grupal perante a sociedade" (SERVA, 1997, p. 23).

Com perguntas abertas, pedia-se aos entrevistados que discorressem sobre os processos básicos; e as informações colhidas por meio das entrevistas gravadas, depois de transcritas, foram tratadas por meio de Análise de Conteúdo (BARDIN, 1977).

Trabalhou-se, na Análise de Conteúdo, com categorias de análise que permitiram identificar as organizações mais conservadoras, ou mais abertas à mudança ou que buscassem a Autotranscendência ou a Autopromoção. No entanto, considerou-se que para identificar as racionalidades e compreender a sua relação com os valores organizacionais, a análise de conteúdo não seria suficiente, recorrendo-se, então, a uma análise inspirada na Análise do Discurso.

Sobre a diversidade da Análise do Discurso, vale salientar que Haidar ${ }^{6}$ (1998), citado por Godoi (2005b), catalogou 34 modelos, considerados como os principais.

Apesar da crítica contundente de alguns autores, a Análise do Conteúdo pode ser situada como "bordeando o limite entre o qualitativo e o quantitativo", não existindo sujeito na leitura do texto, mas somente a descrição e a objetivação dos componentes; produzindo "a perda da dimensão subjetiva e relacional da linguagem, onde reside toda a sua profundidade e espessura" (ALONSO, 1998 apud GODOI, 2005a, p. 4).

Na Análise do Discurso, é importante considerar não somente o que é dito, verbalizado, mas também o que não é dito, trazendo o dito consigo, necessariamente, o não-dito, podendo este ser um pressuposto ou um silêncio (ALVES, 2002c). O não-dizer, também chamado de implícito, tendo como referência Ducrot, é entendido por muitos autores como composto por duas formas de não-dizer, o pressuposto e o subentendido; derivando o primeiro da instância da linguagem e o segundo, daquilo que se dá no contexto (ORLANDI, 2005, p. 82).

Para Maingueneau (1996, p. 94), pode parecer surpreendente a recorrência constante ao implícito, considerando a linguagem como um instrumento de comunicação. A primeira explicação oferecida pelo autor é que o pressuposto é uma

${ }^{6}$ HAIDAR, J. Análisis del discurso. In: CÁCERES, L. J. G. (coord.) Técnicas de investigación en sociedad, cultura y comunicación. México: Prentice Hall, 1998. 
forma de economia, pois "a comunicação seria impossível se não se pressupusesse como adquirido certo número de informações, a partir das quais é possível introduzir novas".

Para participar da pesquisa qualitativa, foram escolhidos os gestores das organizações. A escolha foi realizada de forma intencional, e envolveu sujeitostipo que atendessem aos critérios de representatividade, por seu conhecimento dos fatos e processos, possibilitando, conforme sugere White (1998), levantar o maior número possível de informações sobre o objeto de estudo, estabelecendo e compreendendo o fenômeno em suas diferentes relações.

\section{Apresentação, Anålise e Interpretrção dos Daclos}

Analise quantituatival

Foram coletados 295 questionários nas três ONGs e, após a realização da análise dos valores faltantes e outliers, resultaram 281 questionários válidos, distribuídos conforme a tabela 1 abaixo, por tipo de vínculo e organização.

Tabela 1 - Distribuição dos Questionários Coletados por Organização e Vínculo

\begin{tabular}{lcccccccc}
\hline & \multicolumn{2}{c}{ ALPHA } & \multicolumn{2}{c}{ BETA } & \multicolumn{2}{c}{ GAMMA } & TOTAL & $\%$ PART \\
\hline $\begin{array}{l}\text { VÍNCULO DOS } \\
\text { COLABORADORES }\end{array}$ & $\mathrm{n}$ & $\%$ & $\mathrm{n}$ & $\%$ & $\mathrm{n}$ & $\%$ & $\mathrm{n}$ & \\
\hline CLT & 61 & 88,4 & 155 & 85,2 & 20 & 66,6 & 236 & 84,0 \\
\hline Voluntários & 1 & 1,4 & 7 & 3,8 & 1 & 3,3 & 9 & 3,2 \\
\hline Estagiários & 1 & 1,4 & 8 & 4,4 & 7 & 23,3 & 16 & 5,7 \\
\hline Prestadores de Serviços & 6 & 8,8 & 9 & 5,0 & 2 & 6,7 & 17 & 6,1 \\
\hline Brancos & - & - & 3 & 1,6 & - & - & 3 & 1,0 \\
\hline TOTAL & 69 & & 182 & & 30 & & 281 & 100 \\
\hline
\end{tabular}

Fonte: dados da pesquisa.

Considerando o número de colaboradores de cada organização, já citados, e o número de questionários válidos, nota-se o seguinte percentual de participação em cada organização: Alpha, 17,2\%, Beta, 91,0\%, Gamma, 60,0\%. Considerando o tipo de vínculo do colaborador com a organização, a maior parte dos colaboradores pesquisados compunha-se de pessoas com vínculo empregatício, representando $84,0 \%$ no total.

A organização Gamma apresentou o menor número de questionários válidos na pesquisa, apesar de uma relação questionários/colaboradores de $60,0 \%$, e um significativo número de colaboradores estagiários, talvez como reflexo da coleta ter sido realizada por uma aluna, também estagiária.

De posse dos 281 questionários finais, fez-se uma análise fatorial exploratória das 47 assertivas do instrumento de coleta de dados, as quais foram separadas em duas dimensões bipolares de acordo com a teoria de Schwartz (1992), e de acordo com os fatores propostos por Oliveira e Tamayo (2004).

As fatoriais foram rodadas dimensão a dimensão - Autopromoção, Autotranscendência, Conservação e Abertura à Mudança - com método de extração Maximum Likelihood e Eingevalue maior que 1,0; rotação Oblimin, observandose as comunalidades, as cargas fatoriais e os Alphas de Cronbach. A solução encontrada é apresentada na tabela 2 . 
Tabela 2 - Teoria versus Dados: comparação do conjunto de variáveis por fator

\begin{tabular}{|c|c|c|c|c|}
\hline DIMENSÕES & FATORES & & VARIÁVEIS & ALPHAS \\
\hline \multirow{6}{*}{$\begin{array}{l}\text { AUTOPROMOÇÃO } \\
\text { (variância de } 51,4 \% \text { ) }\end{array}$} & \multirow{2}{*}{ F1 } & TEORIA & $4,8,20,24,36$ & \multirow[b]{2}{*}{0,706} \\
\hline & & DADOS & $4, \quad 20,24$ & \\
\hline & \multirow{2}{*}{ F3 } & TEORIA & $10.18,37,39.42$ & \multirow{2}{*}{0,762} \\
\hline & & DADOS & $10, \quad 37,39$ & \\
\hline & \multirow{2}{*}{ F6 } & TEORIA & $7,25,33,35$ & \multirow{2}{*}{0,647} \\
\hline & & DADOS & 25, & \\
\hline \multirow{4}{*}{$\begin{array}{l}\text { CONSERVAÇÃO } \\
\text { (variância de } 46,4 \% \text { ) }\end{array}$} & \multirow{2}{*}{ F2 } & TEORIA & $11,17,27,28,34,41,43$ & \multirow{2}{*}{0,672} \\
\hline & & DADOS & 34,41 & \\
\hline & \multirow{2}{*}{ F5 } & TEORIA & $6,12,19,31,46$ & \multirow{2}{*}{0,701} \\
\hline & & DADOS & 31,46 & \\
\hline \multirow{4}{*}{$\begin{array}{l}\text { ABERTURA } \\
\text { (variância de } 50,2 \% \text { ) }\end{array}$} & \multirow{2}{*}{ F4 } & TEORIA & $5,9,14,22,32,47$ & \multirow{2}{*}{0,807} \\
\hline & & DADOS & $22,32,47$ & \\
\hline & \multirow{2}{*}{ F7 } & TEORIA & $1,13,23,26,29,30,40$ & \multirow{2}{*}{$\begin{array}{l}45 \\
45\end{array}$} \\
\hline & & DADOS & $13,23,26,29,30$ & \\
\hline \multirow{2}{*}{$\begin{array}{r}\text { AUTOTRANSCENDËNCIA } \\
(\text { variância de } 41,6 \%)\end{array}$} & \multirow{2}{*}{ F8 } & TEORIA & $2,3,15,16,21,38,44$ & \multirow{2}{*}{0,796} \\
\hline & & DADOS & $2,3,15,16,21$, & \\
\hline
\end{tabular}

Fonte: dados da pesquisa.

Observa-se na tabela 2, que a solução encontrada corroborou as duas dimensões bipolares de Schwartz (1992), sendo que todos os fatores de valores organizacionais identificados por Oliveira e Tamayo (2004) foram, de alguma forma, afetados. A dimensão menos afetada foi Autotranscendência, representada pelo fator 8, Preocupação com a Coletividade, seguida de Abertura à Mudança, principalmente, com o fator 7, Autonomia, sendo estas as duas dimensões que mais se assemelham entre os dois questionários: o que se destina a identificar valores organizacionais de empresas privadas e o que foi gerado para identificálos em ONGs. Já no que se refere à Autopromoção e Conservação, são as duas dimensões que apresentam menor semelhança entre os dois questionários.

A seguir, analisou-se a hierarquia dos valores organizacionais das três organizações, tomando-se como base a hierarquia das médias, as quais são apresentadas na tabela 3 .

Tabela 3 - Médias dos Fatores

\begin{tabular}{llccc}
\hline \multirow{2}{*}{ DIMENSÕES } & \multicolumn{1}{c}{ FATORES } & \multicolumn{3}{c}{ MÉDIAS } \\
\cline { 2 - 5 } AUTOPROMOÇÃO & & ALPHA & BETA & GAMMA \\
\cline { 2 - 5 } & F1-Realização & 4,86 & 4,64 & 4,38 \\
\cline { 2 - 5 } & F3-Domínio & 4,81 & 4,24 & 3,97 \\
\hline \multirow{2}{*}{ CONSERVAÇÃO } & F2-Prestígio Organizacional & 5,35 & 4,99 & 5,12 \\
\cline { 2 - 5 } & F5-Tradição & 5,30 & 5,01 & 4,56 \\
\hline ABERTURA & F4-Bem-estar & 4,73 & 4,51 & 3,48 \\
\cline { 2 - 5 } & F7-Autonomia & 4,50 & 4,77 & 3,89 \\
\hline AUTOTRANSCENDÊNCIA & $\begin{array}{l}\text { F8-Preocupação com a } \\
\text { coletividade }\end{array}$ & 5,18 & 5,01 & 4,87 \\
\hline
\end{tabular}

Fonte: dados da pesquisa.

Observa-se que a maior média da organização Alpha e da organização Gamma situam-se no valor Prestigio pertencente à dimensão de Autopromoção, enquanto que, na organização Beta, os valores mais importantes estão representados pelas médias do valor Conformidade, inerente à dimensão Conservação, e pelo valor Preocupação com a Coletividade, relativo à dimensão Autotranscendência. 
Analisando-se do ponto de vista das racionalidades e considerando que o valor Prestígio compõe a dimensão de Autopromoção, as organizações Alpha e Gamma surgem como valorizando ações orientadas pela racionalidade instrumental, enquanto que a organização Beta seria, em princípio, mais orientada pela racionalidade substantiva.

A organização Alpha valoriza, em segundo lugar, o valor Conformidade relativo ao pólo Conservação e, em terceiro lugar, valoriza a Preocupação com a Coletividade, sendo que esta representa a racionalidade substantiva.

Esses dados nos permitem afirmar, e dentro do limite dos mesmos, que a Alpha valoriza ações que lhe proporcionem prestígio junto à sociedade, e que é uma organização conservadora, no que se refere aos costumes e às suas práticas, parecendo orientar-se, primordialmente, pela racionalidade instrumental. Esses dados estão em consonância com a história da organização que se originou e se desenvolveu no contexto da ditadura Vargas, caracterizada por uma visão conservadora e de controle da sociedade, conforme Adriano (2002), preservando ao longo da sua história a natureza assistencial de sua atividade, além de valorizar princípios de produtividade e resultados, amparada em uma ética cristã.

A organização Gamma que também valoriza em primeiro lugar o prestígio perante a sociedade, contempla, em segundo lugar, o valor Preocupação com a Coletividade, mostrando-se mais Autotranscendente do que a organização Alpha, porém também parece ser orientada, primordialmente, pela racionalidade instrumental.

Tais características podem ser melhor compreendidas ao se observar, no site da organização, conforme já destacado, uma ênfase na capacitação acadêmica dos seus gestores, o que pode representar um diferencial em relação às outras organizações do mesmo segmento, e no tripé, que afirmam sustentar a história e as realizações da organização: compromisso com a qualidade, capacidade de inovar e articulação com atores-chave.

A organização Beta, embora valorize em primeiro lugar a Preocupação com a Coletividade, em segundo lugar, valoriza o Prestigio junto à sociedade; porém, é a que menos valoriza Domínio, um valor associado a poder, sinalizando que essa organização orienta-se mais pela racionalidade substantiva do que as demais.

Essas observações parecem estar alinhadas, também, aos modelos de projetos desenvolvidos pela organização Beta, à sua dinâmica de tomada de decisão consensual, à valorização de profissionais envolvidos com o dia-a-dia dos projetos e, principalmente, à sua origem, por ter sido criada em um contexto de repressão política e busca por participação social, conforme destaca Landim (1997).

Considerando, no entanto, que esses resultados nos apontavam pistas quanto a orientação das organizações pesquisadas quanto a racionalidades, era necessário e fundamental que fossemos a campo e entrevistássemos gestores dessas organizações para tentar, por esse meio, identificar as racionalidades pelas quais se orientavam e como teriam relação com os valores organizacionais compartilhados.

\section{Analise qurallitarivival}

Foram realizadas seis entrevistas, sendo três com a organização Alpha e três com a organização Beta. Da organização Alpha foram entrevistados gestores de três projetos sociais, localizados em regiões diferentes e com idade aproximada de 30, 40 e 50 anos, respectivamente, aqui denominados de AE1, AE2, AE3, sendo $A E 1$ e $A E 3$ do gênero feminino e $A E 2$, do gênero masculino. Quanto ao tempo de trabalho na organização, aproximadamente, era de cinco, dez e vinte anos, respectivamente.

Da organização Beta, foram entrevistados a fundadora da organização, com idade aproximada de 60 anos, aqui denominada BE1; a gestora executiva, presente na organização desde a sua fundação, com idade aproximada de 50 anos e, aqui, denominada BE2; e a gestora das relações com os mantenedores, com idade aproximada de 30 anos, aqui denominada BE3, atuando na organização por aproximadamente 5 anos. 
Buscou-se analisar as racionalidades, analisando as falas dos entrevistados quanto às categorias dos pressupostos e subentendidos, à luz dos três problemas fundamentais que toda organização enfrenta, conforme Tamayo (1997): a relação conflitiva entre o indivíduo e o grupo; a necessidade de elaborar uma estrutura para subsistir e a relação da organização com o meio ambiente natural e social.

A seguir, apresenta-se uma síntese dos resultados dessa análise, relativa a cada uma das organizações, destacando-se aspectos que caracterizem determinada racionalidade percebida como predominante ou mais acentuada na organização, com a ressalva que ambas racionalidades são percebidas na mesma organização, falando-se aqui da leitura de um conjunto de dados.

\section{a) Organização Alpha}

A racionalidade instrumental se apresenta preponderante na forma como as decisões são tomadas. De forma centralizada, "projetos são decididos pela administração central e executados pelos coordenadores de campo" (entrevistado $A E 2)$; e quanto à concepção que os dirigentes têm sobre a capacidade de pensar dos que trabalham na organização, segundo eles, "existe uma elite pensante" (entrevistado AE1, em tom jocoso).

Esse aspecto, quanto ao processo decisório e como se concebe quem é capaz de pensar, pressupõe que quem não pertence à elite não pensa, deixando subentendida a concepção de que os seres humanos não são iguais e indica a defesa de valores associados a poder e, portanto, à presença da racionalidade instrumental. Um dos entrevistados compara a hierarquia de Alpha como sendo "parecida com a hierarquia de mercado, de organizações lucrativas" (entrevistado AE3). Vale relembrar que o modelo de gestão adotado na organização em nada difere do modelo de gestão tradicional das organizações lucrativas, em que se tem uma diretoria atuante, ainda que não remunerada nesse caso, cobrando resultados de uma equipe executiva. Esta, por sua vez, desempenha o seu papel de planejamento, organização, execução e controle junto aos demais colaboradores.

$\mathrm{Na}$ análise das entrevistas, à luz dos problemas organizacionais fundamentais citados por Tamayo (1997), observa-se, na relação do indivíduo com a organização, uma ênfase no desempenho do indivíduo e no seu entusiasmo com a organização, mesmo com salários que não acompanham o mercado ou que atrasam algumas vezes. Destaca-se, ainda, a busca por um "fazer mais com menos", refletindo uma pressão por resultados rápidos, exercida pelas empresas e Fundações que apóiam ONGs, conforme destaque dos entrevistados.

Quanto à necessidade de uma estrutura, identificou-se um modelo baseado em responsabilidades, competências e papéis definidos, com projetos definidos por um corpo executivo, os quais podem ser interrompidos, se necessário, dependendo do cumprimento de metas parciais.

Na relação com o ambiente, destaca-se a busca de liderança como referência para outras organizações. Na relação com o Estado, essa organização acaba adaptando-se ao papel de servidora, seguindo a lógica de "quem paga, manda", apesar de criticá-la.

De acordo com Weber (1999), raramente a ação, e particularmente a ação social, orienta-se exclusivamente por uma ou outra racionalidade; o que se aplica à organização Alpha, já que esta se orienta, predominantemente, em sua gestão, pela racionalidade instrumental, mas, também, pela racionalidade substantiva, em alguns de seus propósitos, como "tirar as crianças de uma exposição às drogas e corrupção" (AE3), "cuidar do idoso, visando a sua autonomia" (AE3), "o colaborador deve oferecer um modelo para os jovens" (AE2), entre outras falas que representam exemplos de uma racionalidade substantiva. 


\section{b) Organização Beta}

As análises dos subentendidos e dos pressupostos sugerem que a organização Beta tende para uma racionalidade substantiva em seus objetivos e ações, embora algumas delas sejam aparentemente contempladas por uma racionalidade instrumental.

Declarações como ter por "objetivo combater um mundo de exclusão" (entrevistado BE1), "cuidado com o bem-estar do colaborador com oficinas e terapias" (entrevistado BE3), "projeto para pagamento de mães carentes, para que amamentem e cuidem de seus filhos" (entrevistado BE2) revelam uma preocupação genuína com o ser humano. Por outro lado, percebe-se um processo decisório em que as pessoas, diferentemente da organização Alpha são percebidas como capazes de decidir, de propor, de participar - "os indivíduos que trabalham no campo é que decidem e não a diretoria" (entrevistado BE2). Assim, nos processos decisórios, enfatiza-se a importância da discussão dos problemas e a busca por decisões de consenso, buscando refletir, de forma representativa, a posição do grupo envolvido em determinadas decisões.

$\mathrm{Na}$ organização Beta, a relação do indivíduo com a organização caracteriza-se por priorizar a discussão entre as equipes sobre os projetos que serão selecionados, a sua execução e avaliação. A organização e os indivíduos buscam colocar em prática uma filosofia que combata o mundo desigual ("não é este mundo que eu quero de tanta diferença, de tanta exclusão" BE3), e o colaborador é desafiado a humanizar os processos e a interagir com o grupo. Caso deseje desempenhar o papel de coordenador, existe a liberdade do indivíduo de manifestar os seus anseios, bem como de ser indicado por outro coordenador.

Quanto à necessidade de uma estrutura para o funcionamento, foi declarada a existência de rodízio no exercício da liderança; o líder deve inspirar uma confiança ética, os colaboradores da área administrativa devem manter contato constante com os projetos desenvolvidos, existindo um papel de conselheiro, paralelo ao papel funcional do coordenador. Existe o papel dos auditores dos projetos, mas estes podem não ser atendidos em suas exigências, conforme a avaliação de campo do coordenador.

$\mathrm{Na}$ relação da organização com o seu ambiente, esta assume uma posição crítica quanto às empresas e Fundações apoiadoras, as quais exigem resultados no curto prazo, quando na verdade estão envolvidas questões prioritárias como a manutenção e o suporte à infância, de difícil avaliação no curto prazo, e compreendem que as organizações lucrativas devem "devolver" parte dos seus lucros para a sociedade.

Ainda que a organização Beta tenha como preponderante uma racionalidade substantiva, pode-se observar, também, nas falas dos entrevistados, alguns aspectos relacionados a uma racionalidade instrumental, tais como "render ao máximo os recursos escassos" (entrevistado BE1), "a integração do indivíduo ao grupo é considerado de certa forma obrigatório" (entrevistado BE3), "o empregado ideal dá o máximo de si" (entrevistado BE1).

Encerra-se este tópico lembrando que foi realizada uma síntese das entrevistas à luz das necessidades básicas das organizações sugeridas por Tamayo (1997). Percebeu-se que as organizações não apresentam somente uma ou outra racionalidade, tendo sido estas analisadas quanto a sua predominância.

\section{Discrussão dlos Resrultadlos}

Aspectos relacionados à história das organizações, orientação religiosa/espiritual e processos de controle, como a estrutura hierárquica e de processo decisório, parecem explicar, ainda que em parte, o fenômeno da relação entre os valores organizacionais e as racionalidades instrumental e substantiva. 
A organização Alpha teve sua origem em 1928, em um contexto de forte controle do Estado das chamadas "organizações sociais"; controle este realizado por meio de leis e da liberação de recursos. Realizando, basicamente, um trabalho assistencial ao longo dos anos e dependente até hoje dos recursos do Estado $65 \%$ da receita, em 2003 - , a organização, ao que parece, desenvolveu uma forte hierarquia, a qual é usada para preservar os seus objetivos iniciais.

Outro fator que parece explicar, também, parte dessa relação, refere-se à questão religiosa. Esta é uma organização de origem evangélica e que preservou ao longo dos anos sua identidade, e no Brasil, historicamente, talvez como herança das ditaduras de Vargas e militar, os evangélicos votam regularmente com o governo e têm um forte sentido de obediência às autoridades constituídas (FRESTON, 1994).

E no caso da organização Beta? O que poderia explicar a presença de uma racionalidade mais substantiva? Aqui, também, a origem da organização, talvez, possa esclarecer a associação. A organização surgiu como resultado do trabalho de uma pedagoga nos difíceis anos da década de 70, quando o Governo Militar restringia as associações políticas, mas, ao mesmo tempo, era tolerante com as organizações sociais que buscavam solucionar problemas das comunidades mais carentes, desde que não assumissem críticas diretas ao regime militar. As organizações que surgiram nesse período procuravam dar suporte social aos mais carentes e mantinham relativa distância do Estado, buscando preservar a sua liberdade. (FERNANDES, 1994)

No caso da organização Beta, existe também um componente próximo do religioso, mas não assumido como tal. Como os fundadores ainda presentes na organização seguem os princípios da Antroposofia, e esta defende princípios espiritualistas, aceitando a existência de um mundo não somente físico, tais princípios acabam integrando a organização, os quais são reforçados pela adoção da Pedagogia Waldorf, também ligada à Antroposofia.

A hierarquia desenvolvida na organização, também, ajuda a explicar a relação de uma racionalidade substantiva com os valores organizacionais, pois o modelo adotado procura distribuir o processo decisório entre várias equipes, e ao núcleo central compete preservar os princípios e os valores da organização.

\section{Comclursões}

O objetivo geral desta pesquisa, que consistiu em investigar a relação entre as dimensões bipolares de valores e as racionalidades substantiva e instrumental, foi alcançado mediante duas etapas: a primeira, em que se buscou, por meio da análise da hierarquia dos valores organizacionais, identificar a racionalidade preponderante que permeava cada uma das organizações estudadas; e a segunda, mediante análise de pressupostos e subentendidos, e de dados coletados em entrevistas, verificar se a racionalidade predominante encontrada mediante a pesquisa quantitativa, se confirmava, quando, então, seria possível, de forma mais segura, afirmar que naquelas organizações teria sido encontrada a relação entre valores e racionalidades.

Para orientar a análise qualitativa, adotou-se a perspectiva das funções de valores organizacionais propostas por Tamayo (1997). Os resultados revelaram que as dimensões bipolares de valores organizacionais, propostas pela teoria de Schwartz (1992), guardam íntima relação com a orientação das organizações por racionalidades instrumental e substantiva; apontando que a organização na qual se priorizava a dimensão de Autopromoção era, também, a que se orientava, predominantemente, pela racionalidade instrumental, enquanto a organização que dedicava maior importância à Autotranscendência, guiava-se, na maioria das vezes, pela racionalidade substantiva.

No entanto, assim como os valores estabelecem-se numa hierarquia (ROKEACH, 1973) e, em conseqüência, as organizações não são apenas orientadas para a Autopromoção ou para a Autotranscendência, numa relação mutuamente exclusiva, também as organizações não são permeadas, exclusivamente, por uma outra racionalidade, quer substantiva, quer instrumental. 
Os valores organizacionais são construídos, principalmente, pela influência dos valores de seus líderes, como menciona Oliveira e Tamayo (2004), mas também dos valores culturais da sociedade em que se inserem (HOFSTEDE et al, 1990), como ocorre com as organizações do Terceiro Setor, as quais desenvolvem e compartilham valores que a refletem, podendo se apresentarem como mais instrumentais ou mais substantivas.

Os resultados obtidos indicam que as organizações do Terceiro Setor não são espaços espaços privilegiados para a vivência da racionalidade substantiva, como querem Serva (1993), Vidal et al (2004), e que a presença da racionalidade instrumental não está, necessariamente, associada a "porte, abrangência de atuação, volume de recursos aportados, fiscalização do Ministério Público e influência" (SIQUEIRA PINTO, 2003, p. 340), mas, sim, o contexto sócio-cultural e político em que as ONGs surgem e se desenvolvem é que desempenha papel fundamental no direcionamento por uma ou outra racionalidade.

É no contexto sócio-cultural e político que vão se desenvolver os valores organizacionais que orientarão a vida das organizações. Esses valores configuram no ambiente intra-organizacional uma teia de motivações em que o agir orientado pela racionalidade substantiva e/ou instrumental se cria e recria numa interação dinâmica com os valores, num processo de natureza cultural.

Os estudos têm chamado a atenção para o papel dos fundadores e líderes no desenvolvimento da cultura organizacional (SCHEIN, 1985). Este estudo sinaliza que, no caso das organizações do Teceiro Setor, o papel do líder para a formação dos valores organizacionais (OLIVEIRA; TAMAYO, 2004), os quais fazem parte da cultura organizacional (SCHEIN, 1985; HOFSTEDE et al. 1990), está intimamente ligado ao contexto sócio-cultural-político e ao momento histórico presente na origem das organizações, ou mais precisamente como os fundadores se posicionam frente ao contexto e como frente a este reagem mediante a organização que fundam e/ou lideram.

De acordo com os resultados encontrados, nota-se que os líderes desempenham um papel fundamental na orientação por qualquer uma das racionalidades e dimensões de valores, as quais vão se refletir na relação dos indivíduos com a organização, na estrutura e estilo de gestão, assim como na relação com o ambiente, dando conteúdo às funções dos valores organizacionais, propostas por Tamayo (1997).

Outro aspecto a ser ressaltado como resultado deste trabalho refere-se ao potencial da teoria de valores de Schwartz (1992) para investigar a relação entre valores organizacionais e racionalidades substantiva e instrumental, devido às suas dimensões bipolares de valores e aos procedimentos metodológicos para investigar essa relação.

A abordagem quantitativa teve o mérito de permitir a identificação da hierarquia de valores, possibilitando levantar pressuposições das racionalidades predominantes nas organizações. Já o método qualitativo, em especial a análise dos pressupostos e subentendidos, efetivamente, facilitou verificar as pressuposições apontadas pela pesquisa qualitativa, assim como a relação entre valores e racionalidades. Essa abordagem permitiu um desenvolvimento crítico maior em relação às falas dos entrevistados, oferecendo um suporte teórico para uma meIhor compreensão das organizações como um todo. De forma consciente, e com uma posição mais crítica, foi possível olhar as organizações de uma forma diferenciada, inclusive quanto à sua própria história.

A pesquisa quantitativa sinalizou, ainda, a necessidade de estudar os valores organizacionais das organizações do Terceiro Setor com base na realidade destas e não a partir de instrumento gerado para identificar valores organizacionais de empresas privadas, apesar de ambas serem constituídas dentro do mesmo ambiente sócio-cultural e político. No entanto, as razões de ser e objetivos diferenciam-nas, quanto à formação dos valores.

Conhecer, portanto, racionalidades associadas a valores demanda uma complementaridade de abordagens, contemplando métodos qualitativos que extrapolem o estudo das aparências. 
Por fim, este estudo apresenta limitações, como todo o estudo científico, entre estas a fragilidade do instrumento de pesquisa quantitativa, a Análise do Discurso empregada, que contemplou, apenas, as categorias dos pressupostos e subentendidos e, ainda, o número limitado de casos. Apesar desses limites, no entanto, esperamos poder gerar insights para novas pesquisas, buscando aprofundar o debate sobre as razões que subjazem ao agir instrumental ou substantivo em organizações do Terceiro Setor.

Referêêncials

ADRIANO, Valdir Fernando. A importância do terceiro setor para o planejamento urbano. 104 f. Dissertação (Mestrado em Planejamento Urbano Regional). Instituto de Pesquisa e Desenvolvimento, Universidade do Vale do Paraíba. São José dos Campos, 2002.

ALONSO, L.E. La mirada cualitativa em sociologia. Madrid: Fundamentos, 1998.

ALVES, M.A. Terceiro setor: as origens do conceito. In: ENCONTRO DA ASSOCIAÇÃO NACIONAL DE PÓS-GRADUAÇÃO E PESQUISA EM ADMINISTRAÇÃO, XXVI, 2002, Salvador/BA. Anais... Salvador/BA: 2002a, CD-ROM.

Organizações do terceiro setor e sua(s) racionalidade(s). In: ENCONTRO DA ASSOCIAÇÃO NACIONAL DE PÓS-GRADUAÇÃO E PESQUISA EM ADMINISTRAÇÃO, XXVI, 2002, Salvador/BA. Anais... Salvador/BA: 2002b CD-ROM.

. Terceiro setor: o dialogismo polêmico. 345f. Tese (Doutorado em Administração de empresas). FGV/EAESP, São Paulo, 2002c.

BARDIN, L. Análise de conteúdo. Lisboa: Edições 70, 1977.

FERREIRA, M.C.; ASSMAR, E.M.L.; ESTOL, K.M.F.; HELENA, M.C.C.C.; CISNE, M.C.F. Desenvolvimento de um instrumento brasileiro para avaliação da cultura organizacional. Estudos de Psicologia, v. 7, n. 2, p. 271-280, 2002.

FERNANDES, R.C. Privado porém público. Rio de Janeiro: Relume Dumará. 1994.

FRESTON, P. Evangélicos na política brasileira. São Paulo: Encontro Editora, 1994.

GODOI, C.K. Possibilidades de análise do discurso nos estudos organizacionais: a perspectiva da interpretação social dos discursos. In: ENCONTRO DA ASSOCIAÇÃO NACIONAL DE PÓS-GRADUAÇÃO E PESQUISA EM ADMINISTRAÇÃO, XXIX, 2005, Brasília/DF. Anais... Brasília/DF: 2005a CD-ROM.

- Análise do discurso na perspectiva da interpretação social dos discursos: uma possibilidade aberta aos estudos organizacionais. Gestão.Org, $R e-$ vista eletrônica de gestão organizacional. Pernambuco, v. 3, n. 2, mai./ago. 2005 b. Disponível em < http://www.gestaoorg.dca.ufpe.br/index.htm >. Acesso em 20 out. 2005.

GUERREIRO RAMOS, A. A nova ciência das organizações: uma reconceituação da riqueza das nações. Rio de Janeiro: Editora Fundação Getulio Vargas, 1981.

HOFSTEDE, G. Cultures consequences: international differences in work-related values. Beverly Hills, Sage, 1980.

HOFSTEDE, G.; NEUIJEN, B.; OHAYV, D.D.; SANDERS, G. Measuring organizational cultures: a qualitative and quantitative study across nations. Administrative Science Quarterly, v.35, n.2, 1990.

KABANOFF, B.; HOLT, J. Changes in the espoused values of Australian organizations: 1986-1990. Journal of Organizational Behavior, p. 201-219, may 1996. 
LANDIM, L. Defining the nonprofit sector in developing societies: Brazil. In: SALAMON, Lester M.; ANHEIER, Helmut K. (org.) Defining the nonprofit sector: a cross-national analysis. New York: Manchester University Press, 1997. p. 323349.

MACIEL DE LIMA, S.M.; HOPFER, K.R.; SOUZA-LIMA, J.E. Complementaridade entre racionalidades na construção da identidade profissional. Revista de Administração de Empresas Eletrônica, FGV, v. 3, n. 2, art. 19, jul./dez. 2004.

MAINGUENEAU, Dominique. Pragmática para o discurso literário. São Paulo: Martins Fontes, 1996.

OLIVEIRA, A.F.; TAMAYO, A. Inventário de perfis de valores organizacionais. Revista de Administração, v. 39, n. 2, p. 129-140, abr./mai./jun. 2004.

ORLANDI, E.P. Análise de discurso: princípios e procedimentos. Campinas: Pontes, 2005.

O'REILLY, C.A. III, C.; CHATMAN, J.; CALDWELL, D.F. People and organizational culture: a profile of comparison approach to assessing the personorganization fit. Academy of Management Journal, 34, p. 487-516; 1991.

POLANYI, K. A grande transformação: as origens da nossa época. Rio de Janeiro: Campus, 1975.

ROKEACH, M. The nature of human values. New York (USA): The Free Press, 1973.

SCHEIN, E.H. Organizational culture and leadership. San Francisco (USA): JosseyBass Publishers, 1985.

SCHWARTZ, S. H. Universal in the content and structure of values: theoritical advances and empirical teste in 20 countries. Advances in experimental social psychology, New York, vol. 25, p. 1-65, 1992.

. A theory of cultural values and some implications for work. Applied Psychology: An International Review, 48, 23-47.1999.

SCHWARTZ, S. H.; BILSKY, W. Toward a universal psychological structure of human values. Journal of Personality and Social Psychology, 53, p.550-562, 1987.

SERVA, M. O fenômeno das organizações substantivas. Revista de Administração de Empresas, São Paulo, v. 33, n. 2, p. 36-43, 1993.

. A racionalidade substantiva demonstrada na prática administrativa. Revista de Administração de Empresas, São Paulo, v. 37, n. 2, p. 18-30, 1997.

SIQUEIRA PINTO, W. A racionalidade da práxis administrativa em fundações corporativas. Revista de Administração, São Paulo, v. 38, n. 4, p. 330-342, out./ nov./dez. 2003.

TAMAYO, A. Valores organizacionais. In: TAMAYO, A.; BORGES-ANDRADE, J. E.; CODO, W. (orgs.). Trabalho, organizações e cultura. São Paulo: Cooperativa de Autores Associados, 1997. p. 175-193.

. Valores organizacionais: sua relação com satisfação no trabalho, cidadania organizacional e comprometimento afetivo. Revista de Administração, São Paulo, v. 33, 1998.

TAMAYO, A.; GONDIM, M.G.C. Escala de valores organizacionais. Revista de Administração, São Paulo, v.31, n. 2, p. 62-72, abr/jun. 1996.

TAMAYO, A.; MENDES, A.M.; PAZ, M.G.T. Inventário de valores organizacionais. Estudos de Psicologia, Natal, v. 5, n. 2, p. 289-315, 2000.

TENÓRIO, F. Um espectro ronda o terceiro setor: o espectro do mercado. Revista de Administração Pública, Rio de Janeiro, v. 33, n. 5, p. 85-102, set/out. 1999. 
. (org.) Gestão de ONGs: principais funções gerenciais. Rio de Janeiro: Editora da Fundação Getulio Vargas, 2001.

TEODÓSIO, A.S.S. O terceiro setor de múltiplos atores e de múltiplos interesses: pluralidade ou fragmentação na provisão de políticas públicas? In: ENCONTRO DA ASSOCIAÇÃO NACIONAL DE PÓS-GRADUAÇÃO E PESQUISA EM ADMINISTRAÇÃO, XXVII, 2003, Atibaia/SP. Anais... Atibaia/SP, 2003. CD-ROM.

VIDAL, F.A.B.; MENEZES, M.I.C.B.B.; COSTA, D.P.B; COSTA, S.P.B. Gestão participativa e voluntariado: sinais de uma racionalidade substantiva na administração de Organizações do Terceiro Setor. In: ENCONTRO DA ASSOCIAÇÃO NACIONAL DE PÓS-GRADUAÇÃO E PESQUISA EM ADMINISTRAÇÃO, XXVIII, 2004, Curitiba/PR. Anais... Curitiba/PR: 2004. CD-ROM.

WEBER, M. Economia e sociedade. Brasília: Editora Universidade de Brasília, 1999.

WHITE, O.M. Pesquisa qualitativa. Material ministrado no curso de MBA, da FCAUSP, 1998.

YIN, R. K. Estudo de caso: planejamento e métodos. Porto Alegre: Bookman, 2005.

Artigo recebido em 10/08/2007

Artigo aprovado, na versão final, em 09/04/2009 